\title{
A Cooperative Mechanism Between China Post and Private Express Firm for Remote Area Express Market
}

\author{
Ling YANG \\ School of Management, University of Science and Technology of China, Hefei 230026, China \\ E-mail: yang0909@mail.ustc.edu.cn \\ Juzhi ZHANG \\ School of Management, University of Science and Technology of China, Hefei 230026, China \\ E-mail:zjuzhi@mail.ustc.edu.cn
}

\begin{abstract}
Focusing on the universal express service market, this paper introduces a cooperative mechanism between China Post and private express companies. To investigate whether this cooperative mechanism works, the authors develop a pricing model for the express service market in three different scenarios, i.e., China Post monopolizes the remote area market, competes with a private express company, and cooperatively provides service to the private company. Comparison between the three different scenarios shows that the proposed cooperative mechanism will benefit both firms. The authors also introduce a revenue sharing contract to coordinate the system, and investigate the optimal regulation price.
\end{abstract}

Keywords express service; pricing model; revenue sharing contract; universal postal service; social welfare

\section{Introduction}

In China, although the express industry has been developed greatly in main cities because of the fast developing $\mathrm{B} 2 \mathrm{C}$ e-commerce during the past decade, the express market from cities to remote areas such as pastoral areas, islands, mountains, boarder and so on, is still underdeveloped. Due to the low population density of these remote areas, an express delivery to these areas implies a long distance and a high delivery cost, which prevent most private express firms from entering this market. As a result, this market is currently monopolized by China Post.

China Post, as a national corporation that provides a basic express service for all residents and enjoys corresponding government subsidies and tax breaks, is a large state-owned enterprise supervised by the Chinese treasury department. In the support of fiscal fund, China Post has established the express and transportation network covering all cities and counties (towns) of 31 provinces (autonomous regions and municipalities) nationwide. However, since poor traffic conditions in remote areas and limited transportation capacity to respond express demand nationwide, the quality of China Post's basic express service from cities to remote areas is unsatisfactory.

Received September 26, 2014, accepted October 22, 2014 
In spite of the low quality service, this market cannot be ignored due to the following reasons. Firstly, there are about 270 million of peasant workers. They work and live in main cities, but leave their parents and/or kids living in these remote areas. Thus, they have a huge demand in delivering various products to their families. Secondly, there are another 280 million of people that became urban residents during the past 20 years. For those urban residents they still have relatives or family members living in the remote areas. Thirdly, the latest report shows that there are 178 million peasant Internet users in China, and they could be the potential B2C consumers requiring the express service.

In view of the above facts, some research questions we are interested in include the following: (i) How to improve the express service quality from cities to remote areas while not to increase costs? (ii) How to combine the strengths of China Post and private express firms? (iii) How to fully utilize social resources to get higher economic and social benefits?

In this paper, we propose a cooperation mechanism between China Post and private express firms, under which private firms outsource "the last miles" to China Post. With this mechanism, both the China Post's advantage in its universal postal service network and the efficiency of private firms in their intercity express could be fully utilized. To investigate whether this cooperative mechanism works, we develop a pricing model for the mentioned express market in three scenarios: (i) China Post monopolizes the remote area market; (ii) China Post competes with a private express company without providing "the last mile" outsourcing service; and (iii) China Post cooperatively provides the "last mile" service to the private express firm. We derive the optimal decisions of the system members in the three different scenarios. Comparison between them shows that the proposed cooperative mechanism provides Pareto improvement for both China Post and the private express firm. Furthermore, we analyze the optimal decisions in an integrated scenario and introduce a revenue sharing contract to coordinate the two members.

Previous literatures highly related our research are mainly on the problem of universal postal service. For instance, Pindus et al. ${ }^{[1]}$ constructed the social value system of the universal postal service from eight perspectives, including consumer benefits, business benefits, safety and security, environmental benefits, facility, information exchange, social linkages, and civic pride. Pitia et al. ${ }^{[2]}$ posed that the changing environment of the postal sector has increased the urgency for governments to re-examine public postal administrations. Their study reveals reforms of the Solomon Islands postal service have had some positive influence on the level of customer satisfaction. Schuster ${ }^{[3]}$ showed that privatization has led to a decrease in the quality of the universal service by using a data set on privatization for 21 countries over the period 1980-2007 for the postal sector. Donderl ${ }^{[4]}$ studied a theoretical model assessing the optimal access charges and retail prices in the postal sector. Chen ${ }^{[5]}$ studied the impact of the development of European postal regulation on universal service. Wang and Shen ${ }^{[6]}$ summarized the revelation of Japanese postal reform for improving the compensation mechanism of the universal postal service in China. Wu and Yang ${ }^{[7]}$ analyze the composition of universal postal service cost from four processes namely collecting, processing, transporting and delivering.

Different from previous literatures, our research contributes the literatures in the following ways. First, we provide a cooperation mechanism bringing a Pareto improvement for all participants rather than be focused on the establishment of a "universal service fund". Second, we 
investigate in the perspective of quality improvement of express service from cities to remote areas that were not sufficiently considered in previous literatures. Third, we introduce welfare function to investigate the government's optimal decision based on social welfare maximization.

The remainder of this paper is organized as follows. Section 2 presents model development. Results comparison between three different scenarios is presented in Section 3. In Section 4, integrated system is considered and a revenue sharing contract is introduced. Then we discuss the optimal regulation price based on overall welfare maximization in Section 5. We give numerical analysis in section 6, and conclude our findings in Section 7.

\section{Model Development}

In this paper, we investigate the Niche market of express services from cities to remote areas. The considered market consists of China Post and a private express firm. China Post, as the designated operator of the universal postal union in China, is a national firm to provide the universal postal service to all citizens and is enjoying the government's subsidies and tax breaks. The private express firm, on the other contrary, is running under the market rules. $p_{0}$ denotes the unit service price of China Post, and that of the private express firm is $p_{1}$. We assume that $p_{0}<p_{1}$ because China Post has a mission to satisfy the communication needs of all citizens. Also, we consider that $p_{0}$ is an exogenous variable formulated by government, and $p_{1}$ is the private express firm's decision variable. Although that the network of a private express firm is spread mainly in cities and thus the private company may not cover all the country, it could provide high quality services such as offering door to door pick up service and can delivery the packet quickly. Also, it has few restrictions on the packaging, weight, dimensions, and so on. Different from the private express, China Post's service quality is poor because of its low charges. It doesn't provide pick-up and delivery service, and delivery time is much long. Following the above reasons we assume the service quality of the private express firm $\left(q_{1}\right)$ is higher than that of China Post $\left(q_{0}\right)$, i.e., $q_{0}<q_{1}$. In this paper we analyze three different scenarios for the express market from cities to remote areas, and estimate the profits of the market members to identify a win-win cooperative mechanism for China Post and the private express firm.

As shown in Figure 1, in this first scenario, only China Post provides universal postal service that from cities to remote areas. This scenario is the current situation of China express market. The second scenario considers a possible future situation that the private company enters and competes with China Post in such a market. Under this scenario, a consumer could delivery his packet to a remote area via both China Post and the private express firm. The third one is the cooperative mechanism we proposed, under which while the two firms competes in the market, China Post cooperatively provides the "last mile" service for the private firm.

All the notations and their meanings of this paper are listed in Table 1.

We consider that consumers are heterogeneous in their preferences in the service quality. Specifically, we assume that: (i) The whole market considered is normalized to 1; (ii) A consumer's utility in the service has a linear relationship to the service quality, i.e., $u=v+\theta q$ where the basic utility $v>0$ is a constant to all consumers and $\theta q$ is the utility from the quality; and (iii) the value of $\theta$ is different among consumers and follows a uniform distribution 
$U[0,1]^{[8,9]}$.

For assumption (ii), a more complex model may allow $v$ to vary across the consumers. However, if the basic consumer utility follows uniform distribution, the new model is equivalent to the current model with $v$ being homogeneous ${ }^{[10]}$. For assumption (iii), empirical studies suggest that consumers can be clustered into different market segments based on their service requirements. In addition, the uniform distribution assumption follows a common practice in prior economic literature that model consumer taste on quality (e.g., [11-13]). In these studies, consumers are heterogeneous and the heterogeneous sensitivity parameter is uniformly distributed. Thus, a consumer's surplus in choosing the service of the two firms is $s_{i}=v+\theta q_{i}-p_{i}$ where $i=0$ or 1 .

Usually, a consumer will select the firm that maximizes his surplus. But if his surplus on services of both the two firms are negative, i.e., $s_{i}<0, i=0$ and 1 , he will refuse both firms.

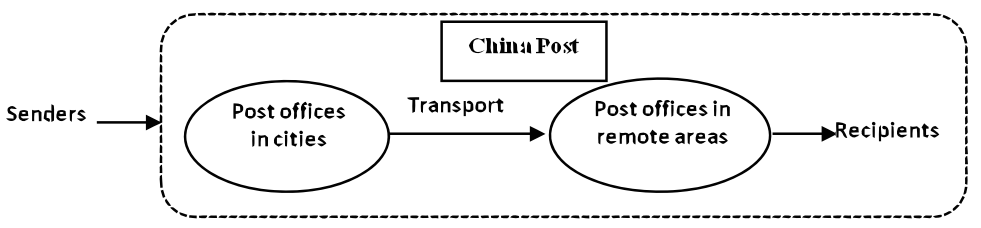

(a) Scenario 1: China Post monopolizes the remote area market

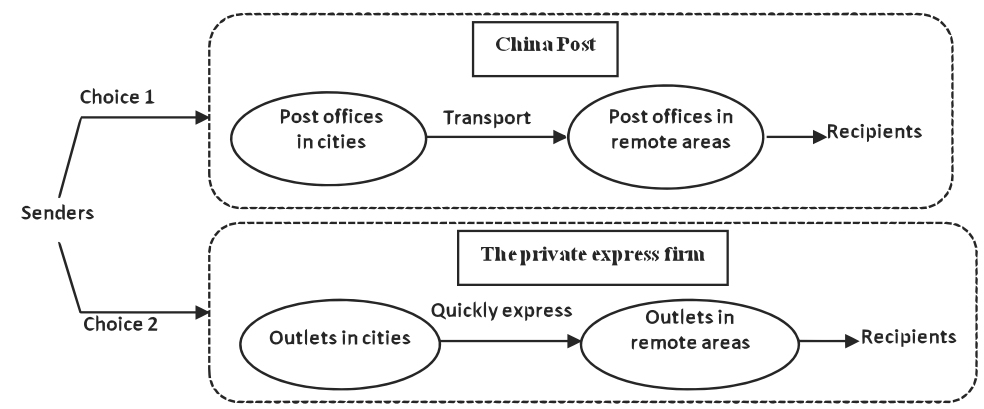

(b) Scenario 2: China Post competes with a private express company without providing "the last mile" outsourcing service

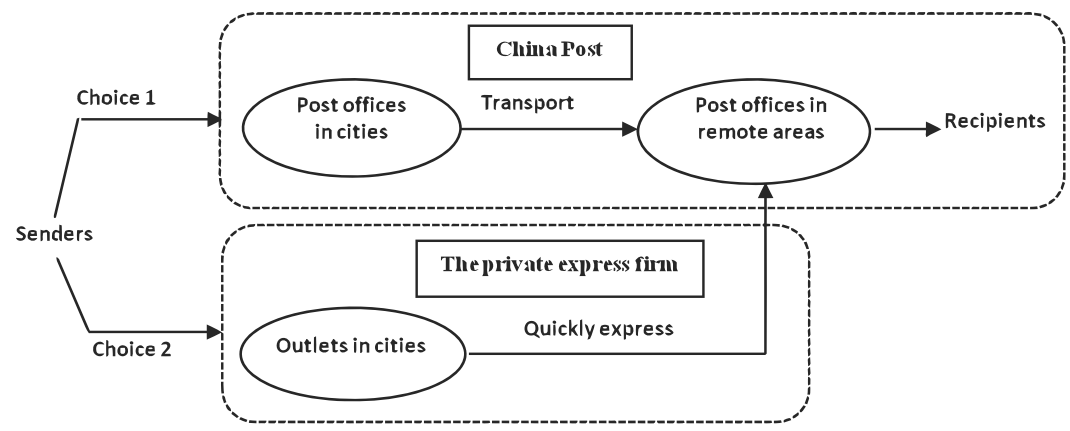

(c) Scenario 3: China Post cooperatively provides the "last mile" service to the private express firm

Figure 1 Three modes of express service 
Table 1 Notations

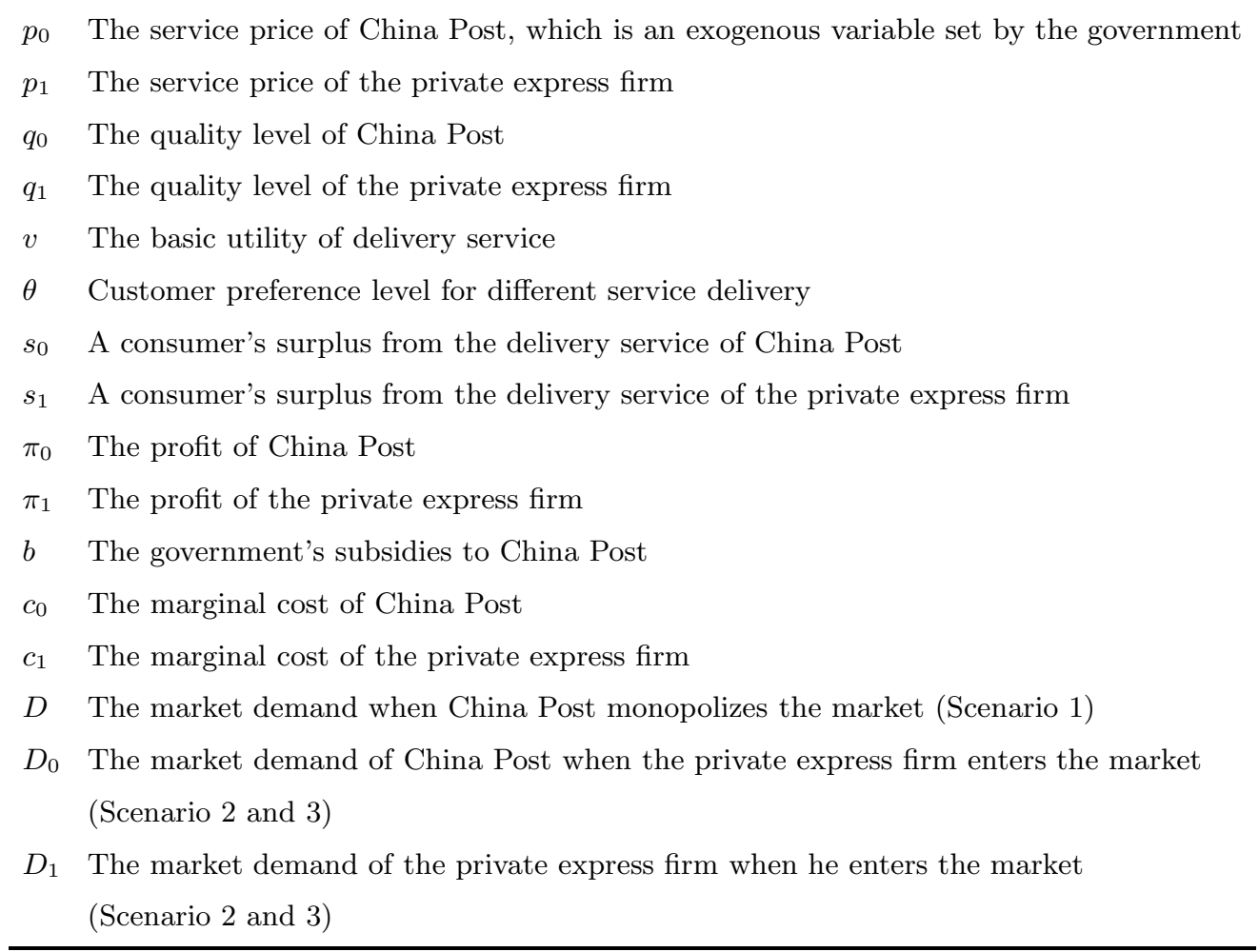

In detail, for the first scenario, consumers can purchase the express service just from China Post, under which his surplus is $s_{o}=v+\theta q_{0}-p_{0}$. Noting that all the consumers that satisfies $v+\theta q_{0}-p_{0} \geqslant$ or $\theta \in[0, \widehat{\theta}]$ (where $\widehat{\theta}=\frac{v-p_{0}}{q_{0}}$ ) will purchase the express service, we know the China Post's demand under such condition is

$$
D_{0}^{(\mathrm{I})}=1-\widehat{\theta}=\frac{q_{0}+v-p_{0}}{q_{0}}
$$

where $0<v<p_{0}$ is assumed. Here the constraint $0<v<p_{0}$ implies that a firm cannot obtain a market with a zero quality service. Then, the profit of China Post is

$$
\pi_{0}^{(\mathrm{I})}=\left(p_{0}+b-c_{0}\right) D_{0}^{(\mathrm{I})}=\frac{\left(p_{0}+b-c_{0}\right)\left(v+q_{0}-p_{0}\right)}{q_{0}}
$$

where $b$ is the government's subsidies to China Post for each delivery, and $c_{0}$ is its marginal cost.

For the second scenario, consumers can purchase service from either China Post or the private express firm. They make their choices to maximize their surplus. A consumer will be indifferent between the two channels if and only if $q_{1}=q_{0}$, or $v+\theta q_{0}-p_{0}=v+\theta q_{1}-p_{1}$. Thus, a consumer with $\theta^{*}=\frac{p_{1}-p_{0}}{q_{1}-q_{0}}$ is indifferent between the two channels. Consumers with $\theta<\theta^{*}$ choose China Post's delivery service, and consumers with $\theta>\theta^{*}$ choose delivery service from the private express firm, i.e.,

$$
D_{0}^{(\mathrm{II})}=\theta^{*}-\widehat{\theta}=\frac{v}{q_{0}}+\frac{p_{1}}{\Delta q}-\left(\frac{1}{\Delta q}+\frac{1}{q_{0}}\right) p_{0}
$$


and

$$
D_{1}^{(\mathrm{II})}=1-\theta^{*}=1-\frac{p_{1}}{\Delta q}+\frac{p_{0}}{\Delta q}
$$

where $\Delta q=q_{1}-q_{0}$. Thus, the profit of China Post is

$$
\pi_{0}^{(\mathrm{II})}=\left(p_{0}-c_{0}+b\right)\left[\frac{v}{q_{0}}+\frac{p_{1}}{\Delta q}-\left(\frac{1}{\Delta q}+\frac{1}{q_{0}}\right) p_{0}\right]
$$

and that of the private express firm is

$$
\pi_{1}^{(\mathrm{II})}=\left(p_{1}-c_{1}\right)\left(1-\frac{p_{1}}{\Delta q}+\frac{p_{0}}{\Delta q}\right)-h
$$

where $h$ is the cost for the private express firm to build and maintain terminal delivery network in remote areas.

The profit function is concave because $\frac{\partial^{2} \pi_{1}^{(\mathrm{II})}}{\partial^{2} p_{1}^{2}}=-\frac{2}{\Delta q}<0$. Let $\frac{\partial \pi_{1}^{(\mathrm{II})}}{\partial p_{1}}=0$, we can get the optimal price for the private express firm

$$
p_{1}^{*(\mathrm{II})}=\frac{1}{2}\left(\Delta q+p_{0}+c_{1}\right)
$$

Substituting Equation (7) into Equation (6), we can get the optimal profit of the private express firm

$$
\pi_{1}^{*(\mathrm{II})}=\frac{1}{4} \frac{\left(p_{0}+\Delta q-c_{1}\right)^{2}}{\Delta q}-h
$$

Equations (7) and (8) show that the private express firm's price and profits are increasing in the service quality difference $\Delta q$ and his rival's price $p_{0}$. Furthermore, if the cost $h$ is very large, the private express firm is not profitable to enter the universal service market without cooperating with China Post.

Duo to $D_{0}^{(\mathrm{I})}=1-\widehat{\theta}=D_{0}^{(\mathrm{II})}+D_{1}^{(\mathrm{II})}$, then $D_{0}^{(\mathrm{II})}<D_{0}^{(\mathrm{I})}$. Compared with first scenario, China Post's demand and profits are negatively influenced by the new entrant in this scenario.

For the third scenario, the two firms compete in the market, and cooperate in the remote area. In detail, the private express firm and China Post charge respectively $p_{0}$ and $p_{1}$ for their express service in the city. In the remote area, the private express firm subcontracts their delivery service orders to China Post with a price $w$. We use the Stackelberg game to model the relationship between the private express firm and China Post. We assume China Post is the leader, and the private express firm is the follower. The private express firm's profit is

$$
\pi_{1}^{(\mathrm{III})}=\left(p_{1}-w-c_{1}\right)\left(1-\frac{p_{1}}{\Delta q}+\frac{p_{0}}{\Delta q}\right)
$$

and the profit of China Post is

$$
\pi_{0}^{(\mathrm{III})}=\left(p_{0}+b-c_{0}\right)\left[\frac{v}{q_{0}}+\frac{p_{1}}{\Delta q}-\left(\frac{1}{\Delta q}+\frac{1}{q_{0}}\right) p_{0}\right]+(w+b)\left(1-\frac{p_{1}}{\Delta q}+\frac{p_{0}}{\Delta q}\right)
$$

In Equation (10), the first term is the profit from China Post's own business, and the second term is the profit from the cooperation with the private express firm.

The following is the sequence of events: China Post first decides the price $w$ that he charges from the private express firm. Then the private express firm decides his service price $p_{1}$ given the subcontracting price $w$. We use the dynamic programming to solve for the optimal solution. To derive the optimal solutions, we first solve for $p_{1}$ by fixing the subcontracting price $w$. Then 
with the obtained responding function $p_{1}(w)$, we solve for the optimal $w$ that maximizes the profit of China Post. The outcome is provided in the following proposition.

Theorem 1 Under the cooperation mechanism, the optimal price decisions of the private express firm and China post are

$$
p_{1}^{*(\mathrm{III})}=p_{0}+\frac{3}{4} \Delta q+\frac{1}{4} c_{1}-\frac{1}{4} c_{0}
$$

and

$$
w^{*}=p_{0}+\frac{1}{2} \Delta q-\frac{1}{2}\left(c_{0}+c_{1}\right)
$$

The profit of the private express firm and China Post are respectively

$$
\pi_{1}^{*(\mathrm{III})}=\frac{1}{16} \frac{\left(\Delta q+c_{0}-c_{1}\right)^{2}}{\Delta q}
$$

and

$$
\begin{aligned}
\pi_{0}^{*(\mathrm{III})}= & \left(p_{0}+b-c_{0}\right)\left(\frac{3 \Delta q-c_{0}+c_{1}}{4 \Delta q}-\frac{p_{0}-v}{q_{0}}\right) \\
& +\left(p_{0}+\frac{1}{2} \Delta q-\frac{1}{2}\left(c_{0}+c_{1}\right)+b\right)\left(1-\frac{3 \Delta q-c_{0}+c_{1}}{4 \Delta q}\right)
\end{aligned}
$$

Proof since $\frac{\partial^{2} \pi_{1}^{(\mathrm{III})}}{\partial^{2} p_{1}^{2}}=-\frac{2}{\Delta q}<0$, the profit function $\pi_{1}^{(\mathrm{III})}$ is concave. Let $\frac{\partial \pi_{1}^{(\mathrm{III})}}{\partial p_{1}}=0$, we can get the responding function $p_{1}(w)$ of the private express firm

$$
p_{1}(w)=\frac{1}{2}\left(p_{0}+\Delta q+w+c_{1}\right)
$$

Substituting Equation (15) into Equation (10) and Letting $\frac{\partial \pi_{0}^{(\mathrm{III})}}{\partial w}=0$, we can derive

$$
w^{*}=p_{0}+\frac{1}{2} \Delta q-\frac{1}{2}\left(c_{0}+c_{1}\right)
$$

Substituting Equation (16) into Equation (15), we can get the optimal price of the private express firm $p_{1}^{*(\mathrm{III})}$. With the optimal $p_{1}^{*(\mathrm{III})}$ and $w^{*}$, we get the optimal profits of the private express firm and China Post.

Theorem 1 shows that the subcontracting price $w$ and the private express firm's service price $p_{1}$ both increase with universal postal service price $p_{0}$. Indeed, given the service quality of China Post, the higher delivery service provided by the private express firm, the more consumers can be attracted. Therefore, the private express firm can gain more profit. Furthermore, China Post can also benefit from the service quality improvement of the private express firm.

\section{Results Comparison}

Comparing the three modes, which are China Post monopolistic mode, competition mode and cooperation mode, we can get Theorem 2 and Theorem 3.

Theorem 2 Comparing the China Post's profits in cooperation mode with that in monopoly mode, we can get

$$
\Delta \pi_{0}=\pi_{0}^{*(\mathrm{III})}-\pi_{0}^{*(\mathrm{I})}=\frac{1}{8} \frac{\left(\Delta q+c_{0}-c_{1}\right)^{2}}{\Delta q} \geqslant 0
$$

Theorem 2 shows that China Post's profit in cooperation mode will be higher than that in China Post monopolistic mode. 
Theorem 3 Comparing the private express firm's profit in cooperation mode with that in competition mode, we have

$$
\Delta \pi_{1}=\pi_{1}^{*(\mathrm{III})}-\pi_{1}^{*(\mathrm{II})}=\frac{1}{16} \frac{\left(\Delta q+c_{0}-c_{1}\right)^{2}}{\Delta q}+h-\frac{1}{4} \frac{\left(\Delta q+p_{0}-c_{1}\right)^{2}}{\Delta q}
$$

Theorem 3 implies that the private express firm benefits from cooperating with China Post when he has a high cost to build and maintain terminal delivery network in remote areas by himself. People has reported that ${ }^{[14]}$, by September of 2012, China Post has about 52,000 outlets throughout the country, among which $70 \%$ are distributed in remote areas, and $18 \%$ of these have an annual income of less than 50,000 Yuan, $8 \%$ have an annual income of less than 20,000 Yuan. However, the average maintenance cost is at least 200,000 Yuan per year per outset. Take a subsidiary of China post in Yushu as an example. Yushu Post just has an income of 1380,000 Yuan per year, but has to spend 8500,000 Yuan a year to maintain and operate its service system. The high maintenance cost is unbearable for the private express firms who subject to shortage of money and pursue for profit maximization. Therefore, the private express firms have strong motivation to cooperate with China Post at the "last mile" when he enters the market.

Theorem 2 and Theorem 3 show that cooperation between China Post and the private express firm is a win-win game. Also, this mechanism is beneficial for customers, who require high quality delivery service and are price-insensitive.

\section{Comparison Between Integrated System and Distributed System}

In the previous section, we have studied the decentralized system, in which China Post and the private express firm are two independent decision makers. They make decisions only depend on their own profit maximization, which will result in "Double Marginalization". Now we investigate the integrated system. We solve the problem of a centralized firm in which the private express firm and China Post are under the same ownership. In this case, the private firm is regarded to provide high-quality and high-price service while China Post is regarded to provide low-quality and low-price service. The profit function of the system is

$$
\Pi=\left(p_{0}+b-c_{0}\right) D_{0}+\left(p+b-c_{1}\right) D_{1}
$$

In Equation (19), the first term is the profits from the customers who choose low-quality delivery service, and the second term is the profits from the customers who choose high-quality delivery service.

Due to $\frac{\partial^{2} \Pi}{\partial^{2} p_{1}}=-\frac{2}{\Delta q}<0$, the profit function in Equation (19) is concave. Let $\frac{\partial \Pi}{\partial p_{1}}=0$, we have

$$
p^{\mathrm{IN}}=p_{0}+\frac{1}{2} \Delta q+\frac{1}{2}\left(c_{1}-c_{0}\right)
$$

Substituting Equation (20) into Equation (19), we can get the optimal profits $\Pi^{\mathrm{IN}}$ in the integrated system. Comparing $\Pi^{\mathrm{IN}}$ with the total profit of the decentralized system, we have

$$
\Delta \pi=\Pi^{\mathrm{IN}}-\left(\pi_{0}^{*(\mathrm{III})}+\pi_{1}^{*(\mathrm{III})}\right)=\frac{1}{16} \frac{\left(\Delta q+c_{0}-c_{1}\right)^{2}}{\Delta q} \geqslant 0
$$

Equation (19) shows that the total profit in integrated system is higher than that in decentralized system. This is the well-known "double marginalization" result of Spengler ${ }^{[15]}$. 
Many remedies for the double marginalization problem have been analyzed during the decades, including competition between retailers, profit sharing, quantity discounts, and adding a manufacturer's direct channel.

In order to remedy the "double marginalization" problem, we use revenue sharing contract (RSC) to coordinate the whole system so that it can achieve the optimal profit in integrated system.

Under RSC, as the game leader, China Post proposes a subcontracting price $w$ and sharing rate $\phi$ to the private express firm, where $0 \leqslant \phi \leqslant 1$ is the private express firm's portions of the sale revenue.

As the game follower, the private express firm's problem for any given RSC contract is to find optimal price to maximize the following profit

$$
\pi_{1}^{\mathrm{RSC}}=\left(\phi p_{1}-w-c_{1}\right) D_{1}
$$

The item $\phi p_{1} D_{1}$ is the sale revenue the private express firm shares, and $(1-\phi) p_{1} D_{1}$ is the sale revenue China Post shares. Assuming $p_{0}+c_{1} \geqslant c_{0}$, we can get the following proposition.

Theorem 4 For any $\phi$ satisfies $\frac{c_{1}}{p_{0}-c_{0}+c_{1}}<\phi<1$, if China Post sets $w^{\mathrm{RSC} *}=\phi\left(p_{0}-\right.$ $\left.c_{0}+c_{1}\right)-c_{1}$, then the proposed RSC contract is a coordinating contract.

Proof Due to $\frac{\partial^{2} \pi_{1}^{\mathrm{RSC}}}{\partial^{2} p_{1}}=-\frac{2 \phi}{\Delta q}<0$, the first-order condition works. Letting $\frac{\partial \pi_{1}^{\mathrm{RSC}}}{\partial p_{1}}=0$, we can get the respond function of the private express firm in RSC:

$$
p_{1}^{\mathrm{RSC}}=\frac{1}{2} \frac{\phi \Delta q+\phi p_{0}+w+c_{1}}{\phi}
$$

Let $p_{1}^{\mathrm{RSC}}$ equal to the optimal price in integrated system. The cooperative price in RSC is derived:

$$
w^{\mathrm{RSC}}=\phi p_{0}-\phi c_{0}+\phi c_{1}-c_{1}
$$

From $p_{1}^{\mathrm{RSC}}=\frac{1}{2} \frac{\phi \Delta q+\phi p_{0}+w+c_{1}}{\phi}, w^{\mathrm{RSC}}=\phi p_{0}-\phi c_{0}+\phi c_{1}-c_{1}, 0<w^{\mathrm{RSC}}<p_{1}^{\mathrm{RSC}}$, and $0<\phi<$ 1 , we can derive that $\phi>\frac{c_{1}}{p_{0}-c_{0}+c_{1}}$ and $\phi<\frac{q_{1}-q_{0}+2 p_{0}-c_{0}+2 c_{1}}{p_{0}-c_{0}+c_{1}}$. Due to $\frac{q_{1}-q_{0}+2 p_{0}-c_{0}+2 c_{1}}{p_{0}-c_{0}+c_{1}}-1=$ $\frac{q_{1}+q_{0}+p_{0}+c_{1}}{p_{0}-c_{0}+c_{1}}>0$, combining with $0<\phi<1$, we can get the value range of revenue sharing coefficient $\phi$ is $\frac{c_{1}}{p_{0}-c_{0}+c_{1}}<\phi<1$.

\section{The Optimal Overall Social Welfare}

In this part, we consider the resolution of the social planner problem. This could be understood as the decision that a government would pursue in order to maximize the welfare of the population who make the use of express service. As is common in the industrial organization literature $^{[16,17]}$, it has been assumed that the social planner cares about total surplus of the relevant population. The welfare function consists of the sum of the service providers and the consumer surpluses.

With these two participants in mind, the total surplus function can be written as:

$$
W=\Pi+C S
$$

where $\Pi\left(\Pi=\pi_{0}+\pi_{1}\right)$ denotes the aggregate profits made by express service providers, or the producer surplus, which correspond to the sum of profits of China Post and the private express firm; CS is consumer surplus which corresponds to the sum of the differences between 
the willingness to pay for the express service and the market price. We investigate the optimal decision of the government aiming to achieve the optimal overall welfare in 3 different scenarios mentioned above, respectively.

In Scenario 1, China Post monopolizes the express market from cities to remote areas. The government pursues the optimal regulated prices by maximizing the following equation:

$$
\begin{aligned}
& \max _{p_{0}} W^{(\mathrm{I})}=\pi_{0}^{(\mathrm{I})}+C S^{(\mathrm{I})} \\
& C S^{(\mathrm{I})}=\int_{p_{0}}^{q_{0}+v} \frac{q_{0}+v-t}{q_{0}} \mathrm{~d} t
\end{aligned}
$$

From $D_{0}^{(\mathrm{I})}=1-\frac{p_{0}-v}{q_{0}}=0$, we can get $\bar{p}_{0}^{(\mathrm{I})}=q_{0}+v$. Duo to $\frac{\partial^{2} W^{(\mathrm{I})}}{\partial^{2} p_{0}}=-\frac{1}{q_{0}}<0$, the overall welfare function in Equation (26) is concave. Let $\frac{\partial W^{(\mathrm{I})}}{\partial p_{0}}=0$, we have

$$
p_{0}^{(\mathrm{I})}+b=c_{0}
$$

which indicates that the optimal regulated price plus subsidy equals the China Post's marginal operation cost.

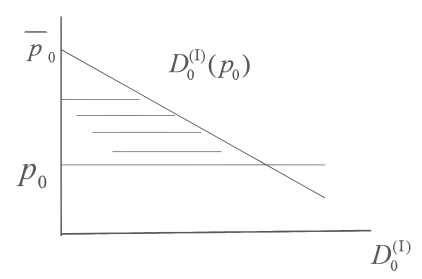

Figure 2 The consumer surplus in Scenario 1

In Scenario 2, China Post competes with a private express company. The overall welfare function in this scenario is

$$
\begin{aligned}
& \max _{p_{0}} W^{(\mathrm{II})}=\pi_{0}^{(\mathrm{II})}+\pi_{1}^{(\mathrm{II})}+C S^{(\mathrm{II})} \\
& C S^{(\mathrm{II})}=\int_{p_{0}}^{\frac{2 v \Delta q+\Delta q q_{0}+c_{1} q_{0}}{q_{0}+2 \Delta q}}\left[\frac{v}{q_{0}}+\frac{p_{1}^{*(\mathrm{II})}}{\Delta q}-\left(\frac{1}{\Delta q}+\frac{1}{q_{0}}\right) t\right] \mathrm{d} t+\int_{p_{1}^{(\mathrm{II})}}^{\Delta q+p_{0}}\left[1-\frac{t}{\Delta q}+\frac{p_{0}}{\Delta q}\right] \mathrm{d} t
\end{aligned}
$$

From $D_{0}^{(\mathrm{II})}=\frac{v}{q_{0}}+\frac{p_{1}^{*(\mathrm{II})}}{\Delta q}-\left(\frac{1}{\Delta q}+\frac{1}{q_{0}}\right) p_{0}=0$ and $D_{1}^{(\mathrm{II})}=1-\frac{p_{1}}{\Delta q}+\frac{p_{0}}{\Delta q}=0$, we can get $\bar{p}_{0}^{(\mathrm{II})}=\frac{2 v \Delta q+\Delta q q_{0}+c_{1} q_{0}}{q_{0}+2 \Delta q}$ and $\bar{p}_{1}^{(\mathrm{II})}=\Delta q+p_{0}$ respectively. Due to $\frac{\partial^{2} W^{(\mathrm{II})}}{\partial^{2} p_{0}}=\frac{q_{0}-4 \Delta q}{4 q_{0} \Delta q}$, we know that equation (29) is concave when differences in service quality are large enough $\left(q_{1}>\frac{5}{4} q_{0}\right)$, otherwise there is no unique optimal value in Equation (29). Letting $\frac{\partial W^{(\mathrm{II})}}{\partial p_{0}}=0$, we can get

$$
p_{0}^{(\mathrm{II})}=\frac{\left(3 \Delta q+2 c_{0}-3 c_{1}-2 b\right)+4 \Delta q\left(c_{0}-b\right)}{4 \Delta q-q_{0}}
$$

In Scenario 3, China post cooperatively provides service to the private company. We can write the overall welfare function in this scenario:

$$
\begin{aligned}
& \max _{p_{0}} W^{(\mathrm{III})}=\pi_{0}^{(\mathrm{III})}+\pi_{1}^{(\mathrm{III})}+C S^{(\mathrm{III})} \\
& C S^{(\mathrm{II})}=\int_{p_{0}}^{\frac{\left(4 v+3 q_{0}\right) \Delta q+\left(c_{1}-c_{0}\right) q_{0}}{4 \Delta q}}\left[\frac{v}{q_{0}}+\frac{p_{1}^{*(\mathrm{III})}}{\Delta q}-\left(\frac{1}{\Delta q}+\frac{1}{q_{0}}\right) t\right] \mathrm{d} t+\int_{p_{1}^{(\mathrm{III})}}^{\Delta q+p_{0}}\left[1-\frac{t}{\Delta q}+\frac{p_{0}}{\Delta q}\right] \mathrm{d} t
\end{aligned}
$$


From

$$
D_{0}^{(\mathrm{III})}=\frac{v}{q_{0}}+\frac{p_{1}^{*(\mathrm{III})}}{\Delta q}-\left(\frac{1}{\Delta q}+\frac{1}{q_{0}}\right) p_{0}=0
$$

and

$$
D_{1}^{(\mathrm{III})}=1-\frac{p_{1}}{\Delta q}+\frac{p_{0}}{\Delta q}=0,
$$

we can get $\bar{p}_{0}^{(\mathrm{III})}=\frac{\left(4 v+3 q_{0}\right) \Delta q+\left(c_{1}-c_{0}\right) q_{0}}{4 \Delta q}$ and $\bar{p}_{1}^{(\mathrm{III})}=\Delta q+p_{0}$. Similar with Scenario 2 , Equation (32) is concave when differences in service quality are large enough $\left(q_{1}>\frac{3}{2} \Delta q\right)$, otherwise there is no unique optimal value in Equation (32) duo to $\frac{\partial^{2} W^{(\mathrm{III})}}{\partial^{2} p_{0}}=\frac{q_{0}-2 \Delta q}{2 q_{0} \Delta q}$. Letting $\frac{\partial W^{(\mathrm{III})}}{\partial p_{0}}=0$, we can get

$$
p_{0}^{(\mathrm{III})}=\frac{\left(2 c_{0}+q_{0}-2 b\right) \Delta q-c_{1} q_{0}}{2 \Delta q-q_{0}}
$$

The government would make different regulation price decision in order to achieve maximum social welfare under the specific one of the 3 different scenarios.

\section{Numerical Analysis}

We present numerical examples to investigate the impact of difference in two service qualities. Our numerical analysis uses following parameter values: $c_{0}=c_{1}=1.5, p_{0}=2, b=0.2$,

\begin{tabular}{|c|c|c|c|c|c|c|}
\hline$\Delta q$ & 1 & 1.5 & 2 & 2.5 & 3 & 3.5 \\
\hline \multicolumn{7}{|c|}{ China Post's profits in monopoly mode } \\
\hline$\pi_{0}^{(\mathrm{I})}$ & 1.4 & 1.4 & 1.4 & 1.4 & 1.4 & 1.4 \\
\hline \multicolumn{7}{|c|}{ Profits and prices in competition mode } \\
\hline$p_{1}^{*(\mathrm{II})}$ & 2.25 & 2.5 & 2.75 & 3 & 3.25 & 3.5 \\
\hline$\pi_{0}^{*(\mathrm{II})}$ & 0.875 & 0.931 & 0.963 & 0.98 & 0.992 & 1 \\
\hline$\pi_{1}^{*(\mathrm{II})}$ & -9.438 & -9.333 & -9.219 & -9.1 & -8.979 & -8.857 \\
\hline \multicolumn{7}{|c|}{ Profits and prices in cooperation mode } \\
\hline$w^{*}$ & 1 & 1.25 & 1.5 & 1.75 & 2 & 2.25 \\
\hline$p_{1}^{*(\mathrm{III})}$ & 2.75 & 3.125 & 3.5 & 3.875 & 4.25 & 4.625 \\
\hline$\pi_{0}^{*(\mathrm{III})}$ & 1.525 & 1.588 & 1.65 & 1.713 & 1.775 & 1.838 \\
\hline$\pi_{1}^{*(\mathrm{III})}$ & 0.063 & 0.094 & 0.125 & 0.156 & 0.188 & 0.219 \\
\hline \multicolumn{7}{|c|}{ Profits and prices in RSC mode } \\
\hline$w^{\mathrm{RSC}}$ & 0.1 & 0.1 & 0.1 & 0.1 & 0.1 & 0.1 \\
\hline$p_{1}^{*(R S C)}$ & 2.5 & 2.75 & 3 & 3.25 & 3.5 & 3.75 \\
\hline$\pi_{0}^{*(R S C)}$ & 1.45 & 1.575 & 1.7 & 1.825 & 1.95 & 2.075 \\
\hline$\pi_{1}^{*(R S C)}$ & 0.2 & 0.3 & 0.4 & 0.5 & 0.6 & 0.7 \\
\hline
\end{tabular}
$s_{0}=1, v=3, h=3$ and $\phi=0.8$.

Table 2 Optimal profits and prices for various $\Delta q$ under different scenarios

Table 2 gives the influence of difference in two service qualities $(\Delta q)$ on the two firm's profits and prices in four different scenarios: China Post monopolistic mode, competition mode, 
cooperation mode, and RSC scenario. In Figures 3-6, we plot the optimal profits and prices for various values of $\Delta q$.

Figure 3 shows that for China Post, it has lowest profit in competition scenario. Its profitability can be improved effectively by cooperating with the private firm. Furthermore, as $\Delta q$ increases, the profits in the four scenarios all increase.

From Figure 4, we observe that the private express firm, with a huge maintenance and operating cost, would be pushed into loss under competition. The cooperation with China Post can improve its plight of the loss. Moreover, the improvement of the service quality can increase private express firm's profits under cooperation and RSC contract.

Figure 5 shows that with the increase of the difference in service quality $(\Delta q)$, the optimal price charged by the private express firm shows a rising trend in different scenarios. Figure 6 shows that: (i) In cooperation scenario, the subcontracting price will increase in the difference in service quality $(\Delta q)$; (ii) Under RSC, the subcontracting price keeps constant when varying the value of $\Delta q$.
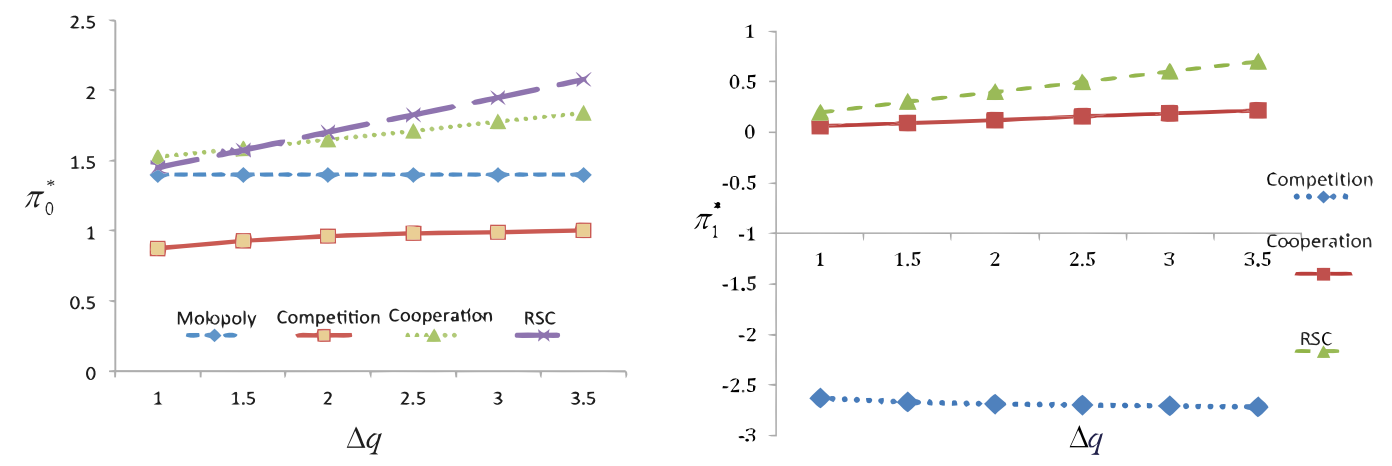

Figure 3 The profits for China Post vs $\Delta q \quad$ Figure 4 The profits for the private express firm vs $\Delta q$

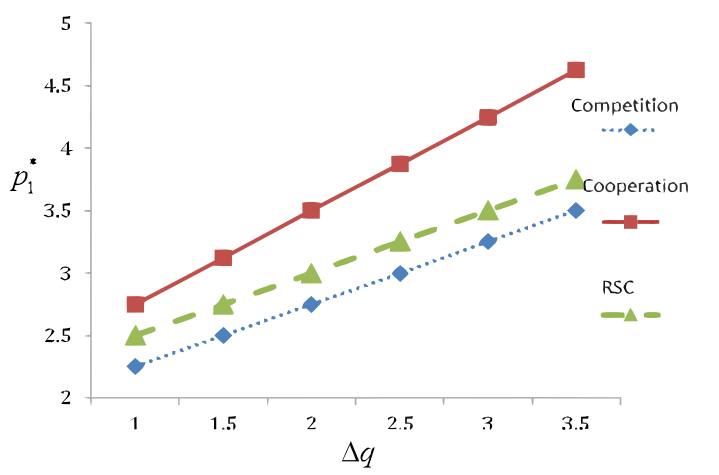

Figure 5 The optimal price $p_{1}^{*}$ vs $\Delta q$

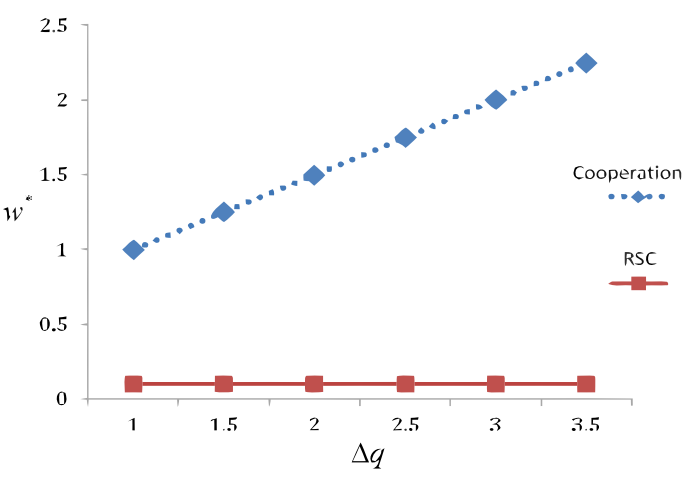

Figure 6 The optimal price $w^{*}$ vs $\Delta q$

\section{Conclusions}

Due to the fast developing $\mathrm{B} 2 \mathrm{C}$ e-commerce, the express industry has been developed in main cities. However, the express market from cities to remote areas is still undeveloped and is monopolized by China Post. The state-owned China Post provides low-price and low-quality 
service for remote areas. Realizing that the high quality service is required by more and more consumers in remote areas, we introduce a cooperative mechanism between China Post and private express firms, in which China Post uses his universal postal service network to deliver the last mile for private firms in the remote area.

To examine whether the proposed cooperative mechanism works or not, we develop pricing models for the express service market in three different scenarios: (i) China Post monopolizes the remote area market; (ii) China Post competes with a private express company and (iii) China Post cooperatively provides service to the private firm. The comparison between these scenarios shows that the proposed cooperative mechanism can benefit both two firms. We also analyze the optimal decisions in the integrated system and introduce a revenue sharing contract to coordinate the system. At last, we investigate the optimal regulation price maximizing social welfare in different scenarios.

This paper just only considers the cooperation mechanism from urban to remote areas, without considering the "reverse cooperation" from remote areas to urban, i.e., the private firm receives orders by the China Post's express network in the remote areas, and then delivers the orders to urban areas. This is because that the price for the universal express services provided by China Post is formulated by government and be restricted to be low. In the "reverse cooperation", the private firm has to charge a relatively high price to keep high-quality service in the remote area, which collides with the limited price principle made by government. Therefore, the reverse cooperation is infeasible under government price regulation.

In addition, although Express Mail Service (EMS) belongs to China Post Group, it is a listed company pursuing profits maximization. The price of EMS courier service is several times higher than that of universal service. In fact, EMS has long-term cooperation with its parent company, China Post. Thus, EMS could be viewed as a private express firm in this paper.

There are several directions in which to extend our paper. One possible extension of our model is to consider the case of multiple private firms who directly compete with each other. Additionally, while we consider only the valuation is a constant to all consumers, we can relax the assumption to get some more general results.

\section{References}

[1] Pindus N, Brash R, Franks F, et al. A framework for considering the social value of postal services. Postal Regulatory Commission, 2010.

[2] Pitia N, Singh G, Postal N R. Service reforms in Solomon Islands of the South Pacific: Evaluating consequences for public service delivery and customer satisfaction. International Journal of Public Administration, 2013, 36(12): 821-830.

[3] Schuster P B. One for all and all for one: Privatization and universal service provision in the postal sector. Applied Economics, 2013, 45(26): 3667-3682.

[4] Donderl P D. Access pricing in the postal sector: Theory and simulations. Review of Industrial Organization, 2006, 28(3): 307-326.

[5] Chen Y. The rising trend of postal logistics market in Nordic. People's Posts and Telecommunications News, 2005-04-27.

[6] Wang D Y, Shen S D. The revelation of Japanese postal reform for improving the compensation mechanism of the universal postal service in China. Industrial Technology Economy, 2010(4): 18-20. 
[7] Wu L F, Yang N D, Yang F. Costing of universal postal service. Modern Economic Science, 2009, 31(4): 76-79.

[8] Garca D, Tugores M. Optimal choice of quality in hotel services. Annals of Tourism Research, 2006, 33(2): 456-469.

[9] Dumrongsiri A, Fan M, Jain A, et al. A supply chain model with direct and retail channels. European Journal of Operational Research, 2008, 187: 691-718.

[10] Cattani K, Gilland W, Heese S, et al. Boiling frogs: Pricing strategies for a manufacturer adding an internet channel. Production and Operations Management, 2006, 15(1): 40-56.

[11] Gabszewicz J, Thisse J. Price competition, quality and income disparities. Journal of Economic Theory, 1979, 20: 340-359.

[12] Shaked A, Sutton J. Natural oligopolies. Econometrica, 1983, 51(5): 1469-1483.

[13] Shaked A, Sutton J. Product differentiation and industrial structure. The Journal of Industrial Economics, 1987, 36(2): 131-146.

[14] Nie C X, Niu Y. The documentary of China universal postal service. http://finance.people.com.cn/n/ 2012/0924/c348950-19089292.html (September 24, 2012).

[15] Spengler J J. Vertical integration and antitrust policy. Journal of Political Economy, 1990, 80(5): 347-352.

[16] Marius S. Third-degree price discrimination and output: Generalizing a welfare result. The American Economic Review, 1950, 58(4): 1259-1262.

[17] Hal R V. Price discrimination and social welfare. The American Economic Review, 1985, 75(4): 870-875. 